\section{Defibrotide for the treatment of hepatic veno-occlusive disease/sinusoidal obstruction syndrome with multiorgan failure}

\author{
Paul G Richardson*,1, Stephan A Grupp ${ }^{2}$, Antonio Pagliuca ${ }^{3}$, Amrita Krishnan4, \\ Vincent $\mathrm{T} \mathrm{Ho}^{5}$ \& Selim Corbacioglu ${ }^{6}$
}

Hepatic veno-occlusive disease, also called sinusoidal obstruction syndrome (VOD/SOS), is a potentially life-threatening and unpredictable complication of hematopoietic stem cell transplantation (HSCT). Characterized by a prothrombotic-hypofibrinolytic state, VOD/SOS typically presents with hyperbilirubinemia, ascites, weight gain and painful hepatomegaly; VOD/SOS with multiorgan failure may be associated with $>80 \%$ mortality. Treatment has been mainly supportive. However, defibrotide is now approved in the USA for treatment of hepatic VOD/SOS with renal or pulmonary dysfunction following HSCT and in the EU for treatment of severe hepatic VOD/SOS post-HSCT. In vitro evidence suggests defibrotide may restore thrombotic-fibrinolytic balance at the endothelial level and protect endothelial cells. Defibrotide has demonstrated significant reduction in VOD/SOS-related mortality and resolved VOD/SOS-related symptoms, with a manageable safety profile.

First draft submitted: 2 May 2017; Accepted for publication: 30 June 2017; Published online: 11 August 2017

Hepatic veno-occlusive disease, also called sinusoidal obstruction syndrome (VOD/SOS), is a potentially life-threatening and unpredictable complication of toxic injury mainly from conditioning regimens for hematopoietic stem cell transplantation (HSCT) [1,2]. Although less common, VOD/SOS also may develop as a result of primary chemotherapy, immunotoxin conjugated therapies or radiation, particularly in children [1-4]. Mean prevalence of VOD/SOS among postHSCT patients was estimated to be $13.7 \%$ (95\% confidence interval $[\mathrm{CI}]=13.3-14.1 \%)$, based on a review of 135 studies, each conducted in more than 50 patients between 1979 and 2007 [5]. VOD/SOS with multiorgan failure (MOF; also sometimes referred to as multiorgan dysfunction) occurs in an estimated $30-40 \%$ of patients with VOD/SOS after HSCT [6], and carries a mortality rate that exceeds $80 \%$ [5]. Children differ substantially from adults, with an incidence of VOD/ SOS approximately two- to three-fold higher overall [4,7-9], and rates as high as $30-60 \%$ in highrisk subpopulations like infants and those with inherited diseases like familial hemophagocytic lymphohistiocytosis, thalassemia [10] and osteopetrosis [7,11,12]. Clinical presentation also differs in children, who often lack hyperbilirubinemia $[4,7,13,14]$, the hallmark of VOD/SOS.

\footnotetext{
Jerome Lipper Multiple Myeloma Center, Dana-Farber Cancer Institute, Harvard Medical School, Boston, MA, USA

${ }^{2}$ Pediatric Oncology, The Children's Hospital of Philadelphia \& the Perelman School of Medicine at the University of Pennsylvania, Philadelphia, PA, USA

${ }^{3}$ Department of Haematological Medicine, King's College Hospital, London, UK

${ }^{4}$ Department of Hematology \& Hematopoietic Cell Transplantation, City of Hope, Duarte, CA, USA

${ }^{5}$ Hematopoietic Stem Cell Transplantation, Dana-Farber Cancer Institute, Boston, MA, USA

${ }^{6}$ Department of Pediatric Hematology, Oncology \& Stem Cell Transplantation, University of Regensburg, Regensburg, Germany

*Author for correspondence: paul_richardson@dfci.harvard.edu
}

\section{KEYWORDS}

- defibrotide $\bullet$ diagnostic criteria $\bullet$ efficacy

- mechanism of action

- multiorgan dysfunction

- pathophysiology • safety

- sinusoidal obstruction

syndrome $\bullet$ treatment

- veno-occlusive disease

Future $\because:$ Medicine 
Development of VOD/SOS after HSCT involves a complex pathophysiologic cascade initiated by the toxic injury from the conditioning regimen, with subsequent endothelial-cell damage and activation, and a prothrombotichypofibrinolytic state leading to central venous occlusion and/or sinusoidal obstruction $[1,15,16]$. The initial toxic injury occurs to sinusoidal endothelial cells and hepatocytes in zone 3 of the liver acinus. Because endothelial cells help regulate the equilibrium between pro- and antithrombotic factors, their injury may lead to progressive deterioration of thrombofibrinolytic balance, with potentially reinforcing feedback loops leading to further damage, as well as cytokine release from the injured tissue [15]. Structurally, the injured endothelial cells compromise the integrity of the fenestrated sinusoidal endothelium. The sinusoidal endothelial cells round up, allowing for gaps in the sinusoidal barrier and extravasation of blood, leucocytes and cellular debris into the space of Disse under the endothelial cells [17]. This leads to dissection of the endothelial lining and sloughing of sinusoidal cells, which embolize downstream, causing obstruction of sinusoidal flow [17]. In addition, endothelial cell injury leads to upregulation of prothrombotic pathways, resulting in platelet activation, platelet and leukocyte adhesion, fibrin-related aggregates $[1,3,15,18]$. These events are followed by further deterioration of the vasculature, thickening of the subintimal zone, sclerosis and narrowing of the venular lumen $[3,15]$. The profound endothelial dysfunction, possibly accompanied by inflammation, results in portal hypertension, hepatorenal syndrome, obliteration of terminal hepatic venules and potential for MOF and death $[1-3,16,19]$.

The hallmark clinical signs/symptoms of VOD/SOS include hyperbilirubinemia, painful hepatomegaly, weight gain and ascites $[1,16]$. Diagnosis of VOD/SOS has traditionally been determined via either the Baltimore criteria bilirubin $\geq 2 \mathrm{mg} / \mathrm{dl}$ plus two or more of hepatomegaly, ascites, and weight gain $\geq 5 \%$, occurring within $\leq 21$ days of HSCT [20], or the modified Seattle criteria - two or more of bilirubin $>2 \mathrm{mg} / \mathrm{dl}$, hepatomegaly or right upper quadrant pain and $>2 \%$ weight gain (a weight gain threshold of $>5 \%$ is sometimes used) [19,21]. An expert committee of the European Society for Blood and Marrow Transplantation (EBMT) recently proposed new criteria for diagnosis and grading of the severity of $\mathrm{VOD} / \mathrm{SOS}$ in adults, based on increased epidemiologic data showing that the traditional criteria do not encompass all of the various clinical manifestations of VOD/SOS [17,22]. These include VOD/SOS with onset beyond 21 days postHSCT [17], which has been reported in 15-20\% of cases $[23,24]$ and often presents without hyperbilirubinemia [17]. Consequently, the EBMT has proposed new diagnostic criteria for adults that distinguish 'classical' VOD/SOS occurring within 21 days after HSCT, using the Baltimore criteria for these patients, and 'late-onset' VOD/ SOS, occurring > 21 days after HSCT [22]. New EBMT diagnostic criteria for $\mathrm{VOD} / \mathrm{SOS}$ that are specifically for pediatric patients were recently published; these pediatric criteria differ in some aspects from those for adults [4]. For example, there is no limitation for time of onset for pediatric patients. In addition, the new EBMT pediatric criteria require a rise in bilirubin from an individual baseline for three consecutive days or bilirubin $\geq 2 \mathrm{mg} / \mathrm{dl}$ within $72 \mathrm{~h}$, rather than simply stipulating a predefined level of hyperbilirubinemia at presentation, as in adults. Also, given that a $2 \%$ weight gain, as required by the Seattle criteria, can be misleading in children, new EBMT pediatric criteria require weight gain on three consecutive days, excluding other plausible causes, and refractoriness to diuretic treatment, or a weight gain of more than $5 \%$ above baseline, as a criterion for children. The pediatric criteria also adopted refractoriness to platelet transfusions as a sensitive and early diagnostic criterion reflecting best the endothelial nature of the disease, which had already been described decades ago by McDonald et al. [19] and later confirmed in several publications $[16,18]$.

Risk factors for VOD/SOS include both patient-related factors such as age, gender and genetic characteristics, including specific genotype subgroups of HPSE single nucleotide polymorphisms (SNPs) [25], as well as conditioning regimen-related variables (Box 1) $[1,2,22,26]$. Although regimen-related risk factors are similar in adults and children, the impact of patientrelated risk factors is greater in children than in adults [4]. Both varying presence of risk factors in study populations and use of the Baltimore or modified Seattle criteria for identification and diagnosis of VOD/SOS across studies have contributed to the wide range in VOD/SOS prevalence rates reported in post-HSCT patients [5]. The review of 135 studies with VOD/SOS prevalence and outcome data for post-HSCT patients 
Box 1. Risk factors for veno-occlusive disease/sinusoidal obstruction syndrome.

Transplant/conditioning regimen related

- Unrelated donor ${ }^{+}$

- HLA-mismatched donor ${ }^{t}$

- Myeloablative conditioning regimen ${ }^{\dagger}$.

- High-dose busulfan-based conditioning regimen ${ }^{+}$

- High-dose TBI-based conditioning regimen ${ }^{+}$

- Non-T-cell depleted graft ${ }^{+}$

- Second $\mathrm{HSCT}^{+}$

- Allogeneic HSCT > autologous HSCT

- Cyclophosphamide-containing regimens

- Cyclophosphamide after high-dose busulfan

- Peripheral blood HSCT versus BMT

- Interval between diagnosis of malignancy and transplant $>12$ months

- Sirolimus + tacrolimus GVHD prophylaxis (sirolimus/tacrolimus + methotrexate $>$ sirolimus/tacrolimus alone)

Patient \& disease related

- Older > younger (in adult patients) ${ }^{\dagger}$

- Female receiving norethisterone ${ }^{t}$

- Karnofsky score $<90 \%{ }^{+}$

- Gene polymorphism (GSTM1, GSMTT1, HPSE) ${ }^{+}$

- Advanced disease (beyond second CR or relapse) ${ }^{+}$

- Metabolic syndrome ${ }^{t}$

- Thalassemia ${ }^{+}$

- Deficit of AT III, tPA and resistance to APC

- Myelofibrosis

- Inborn errors of metabolism

- Immunodeficiency

- Deteriorated health status $\leq 30$ days before transplant

- Impaired pulmonary function

Hepatic-related risk factors

- $A L T / A S T>2.5 \times U L N^{+}$

- Serum bilirubin $>1.5 \times \operatorname{ULN}^{+}$

- Cirrhosis ${ }^{t}$

- Active viral hepatitis ${ }^{\dagger}$

- Hepatic irradiation ${ }^{+}$

- Previous use of gemtuzumab ozogamicin or inotuzumab ozogamicin ${ }^{\dagger}$

- Use of hepatotoxic drugs ${ }^{t}$

- Iron overload ${ }^{+}$

- Hepatic fibrosis

Pediatric-specific risk factors

- Hemophagocytic lymphohistiocytosis, Griscelli syndrome, X-linked hydroproliferative disease, infantile osteopetrosis, thalassemia

- Busulfan-melphalan-based auto-HSCT in neuroblastoma

- Infant age group

- Low weight

†Presence of $\geq 2$ of these risk factors indicates that VOD/SOS severity for adults is one grade higher than determined by clinical symptoms alone in Table 1.

BMT: Bone marrow transplantation; CR: Complete response; EBMT: European Society for Blood and Marrow Transplantation; GVHD: Graft-versus-host disease; HSCT: Hematopoietic stem cell transplant; TBI: Total body irradiation; ULN: Upper limit of normal.

Adapted with permission from Nature Publishing Group [17] $\odot$ as licensed under a Creative Commons Attribution-NonCommercialNoDerivs 4.0 International License (2015).

Additional content has been adapted with permission from John Wiley \& Sons [2] ๑ (2006) and from the American Society for Blood and Marrow Transplantation [26] @ (2016). 


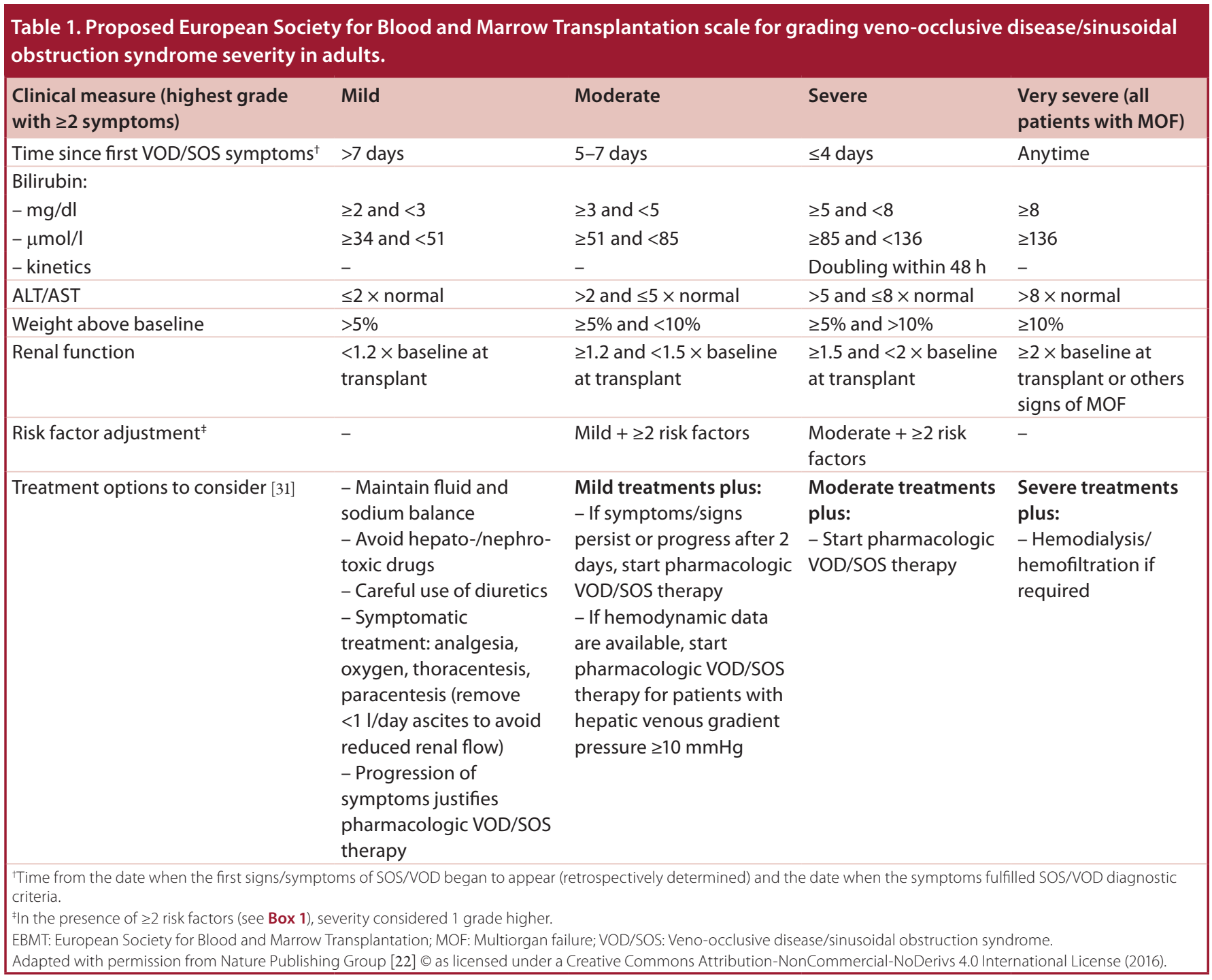

found that the absolute incidence rates reported in individual studies ranged from 0 to $62 \%$ [5]. A variety of clinical factors also appear to be increasing patient risk of VOD/SOS, including expansion of HSCT populations and increased use of specific conditioning agents such as intravenous (IV) busulfan in children, sirolimus and everolimus [5]. However, other clinical factors, including increased use of reduced intensity conditioning (RIC) regimens, may reduce risk, and treatment of VOD/SOS with defibrotide has improved survival [6]. Nonetheless, a study found that even among 271 patients receiving allogeneic HSCT and RIC regimens, VOD/ SOS incidence was still a considerable $8.8 \%$ [27].

Even with best supportive care, risk of mortality from VOD/SOS with MOF remains high. The 135-study review estimated a mortality rate of $84.3 \%$ for VOD/SOS with MOF based on 19 studies reporting this outcome for the period 1979-2007 [5]. A Japanese registry study assessing 4290 patients who had undergone allogeneic HSCT between 1999 and 2010 found that among those with VOD/SOS (Baltimore criteria) with MOF, mortality at post-HSCT Day +100 was $85 \%$; the rate for patients without MOF was 56\% [28]. By contrast, patients without VOD/SOS post-HSCT had an overall Day +100 mortality rate of $24 \%$. This is corroborated in children, where a fourfold increase in overall mortality independently of the severity of VOD/SOS was observed $[7,8]$. Among patients who died post-HSCT, mortality was VOD/SOS-related in a substantial proportion of patients without MOF (41\%), and in the majority of patients with MOF (61\%; $\mathrm{p}<0.001$ between groups) [28]. A US-HSCT registry study for the period of 2008-2011 
reported a mortality rate of $69.1 \%$ at Day +100 for 55 patients with VOD/SOS and MOF given standard of care [29]. In addition, a clinical trial reported that Day +100 post-HSCT mortality was $75 \%$ among control patients with VOD/SOS and MOF following HSCT received between 1995 and $2007(n=32)$ [30]. Mortality risks other than MOF in patients with VOD/SOS have not been widely investigated. However, patients diagnosed via the Baltimore criteria have been observed to have higher death rates than those diagnosed with the Seattle criteria [5]. A pediatric study also found that mortality predictors in 19 patients with VOD/SOS post-HSCT included donors other than autologous or matched sibling; hepatic and cutaneous graft-versus-host disease (GVHD); maximal weight gain $>9 \%$; peak bilirubin $>300 \mu \mathrm{mol} \mathrm{1}^{-1}$, Day +21 bilirubin $>200 \mu \mathrm{mol} 1^{-1}$ and a rise of bilirubin $>15 \mu \mathrm{mol} 1^{-1}$ and more than three of these predictors combined [31]. Together, these data illustrate the high mortality rates associated with VOD/SOS with MOF or other risk factors and highlight the medical need for effective treatments [17,21].

Management of VOD/SOS has traditionally been supportive, focused toward maintaining intravascular volume and organ perfusion $[17,21]$. However, this scenario has now changed considerably with the availability of defibrotide, which has a favorable risk/benefit profile [21], as the first drug approved for the treatment of VOD/SOS [17]. Guidelines for the management of VOD/SOS, issued jointly in 2013 by the British Committee for Standards in Haematology (BCSH) and the British Society for Blood and Marrow Transplantation (BSBMT), recommend [21]:

- Treatment with IV defibrotide, $25 \mathrm{mg} / \mathrm{kg}$ total daily $(6.25 \mathrm{mg} / \mathrm{kg}$ every $6 \mathrm{~h}$ given as a $2-\mathrm{h} \mathrm{IV})$;

- Consideration of high-dose methylprednisolone, with caution regarding infection;

- Vigilant supportive care in the management of fluid balance;

- Consultation with critical care and hepatology specialists;

- Optional use of transjugular intrahepatic portosystemic shunt (TIPS) or hepatic transplantation.

Cases of VOD/SOS associated with a dismal prognosis were traditionally characterized retrospectively based on outcomes or, more recently, prospectively based on the presence of MOF [5,16,17,21]. More nuanced guidelines for prospective grading of VOD/SOS and selecting appropriate treatment strategies are currently being established. The EBMT has proposed a grading system for adult patients, which is divided into five categories, as in the Common Terminology Criteria for Adverse Events: grade 1 = mild; grade 2 = moderate; grade 3 = severe; grade $4=$ very severe and grade $5=$ death. These categories are based on clinical indicators including time to onset of symptoms, bilirubin level and velocity, liver and renal function test values, weight gain and presence of $\geq 2$ risk factors (Table 1) [22]. More recently, the EBMT issued a similar grading system specifically for pediatric patients (Table 2) [4].

\section{Overview of VOD/SOS therapies \\ - Supportive \& other treatments}

Treatment of VOD/SOS has traditionally included symptomatic and remedial therapies, which allow time for spontaneous resolution in milder cases but are generally ineffective in severe VOD/SOS [17,21,32,33]. Supportive measures such as maintaining fluid and sodium balance, analgesia, avoidance of hepato- and nephro-toxic medications, and close monitoring of renal function remain essential components of management $[21,32,33]$. Addition of therapeutic paracentesis, hemofiltration (continuous veno-venous hemodialysis), ventilator support and TIPS may be necessary for some patients $[17,21,32]$. TIPS has been suggested as an option after failure of medical treatment for severe portal hypertension associated with VOD/SOS, based on some evidence of its clinical benefit [34-37]. However, supportive care may be insufficient for patients with moderate VOD/SOS and particularly for patients with VOD/SOS and MOF, who require specific therapy $[17,21]$. It is also important to recognize that the progression of VOD/SOS from initially "mild" to "severe" and "very severe" is unpredictable and can be swift [22].

Medical treatments for VOD/SOS that have been investigated include tPA, methylprednisolone and $\mathrm{N}$-acetylcysteine [21]. Two clinical studies of moderate size assessing tPA and heparin treatment for VOD/SOS ( $\mathrm{n}=42$ and $\mathrm{n}=37$ ) [38,39], and one trial of tPA with and without heparin $(\mathrm{n}=56)$ [39] have reported response to tPA (resolution or improvement of VOD/ SOS symptoms) in approximately $23-52 \%$ of 


\begin{tabular}{|c|c|c|c|c|}
\hline Clinical measure & Mild & Moderate & Severe & Very severe (MOD/MOF) \\
\hline CTCAE & 1 & 2 & 3 & 4 \\
\hline $\begin{array}{l}\text { Liver function tests }{ }^{\ddagger} \\
\text { (ALT, AST, GLDH) }\end{array}$ & $\leq 2 \times$ normal & $>2$ and $\leq 5 \times$ normal & & $>5 \times$ normal \\
\hline Persistent $\mathrm{RT}^{\ddagger}$ & $<3$ days & 3-7 days & & $>7$ days \\
\hline \multicolumn{5}{|l|}{ Bilirubin: } \\
\hline$-\mathrm{mg} / \mathrm{dl}^{\ddagger \S}$ & & $<2$ & & $\geq 2$ \\
\hline$-\mu \mathrm{mol} / \mathrm{l}$ & & $<34$ & & $\geq 34$ \\
\hline Ascites $^{\ddagger}$ & Minimal & Moderate & \multicolumn{2}{|c|}{$\begin{array}{l}\text { Necessity for paracentesis (external } \\
\text { drainage) }\end{array}$} \\
\hline Bilirubin kinetics & - & - & - & Doubling within $48 \mathrm{~h}$ \\
\hline Coagulation & Normal & Normal & $\begin{array}{l}\text { Impaired } \\
\text { coagulation }\end{array}$ & $\begin{array}{l}\text { Impaired coagulation } \\
\text { with need for } \\
\text { replacement of } \\
\text { coagulation factors }\end{array}$ \\
\hline $\begin{array}{l}\text { Renal function } \\
\text { GFR (ml/min) }\end{array}$ & $89-60$ & $59-30$ & $29-15$ & $<15$ (renal failure) \\
\hline $\begin{array}{l}\text { Pulmonary function } \\
\text { (oxygen requirement) }\end{array}$ & $<21 / \min$ & $>2 \mathrm{l} / \mathrm{min}$ & \multicolumn{2}{|c|}{$\begin{array}{l}\text { Invasive pulmonary ventilation (including } \\
\text { CPAP) }\end{array}$} \\
\hline CNS & Normal & Normal & Normal & $\begin{array}{l}\text { New-onset cognitive } \\
\text { impairment }\end{array}$ \\
\hline \multicolumn{5}{|c|}{$\begin{array}{l}\text { IIf a patient fulfills criteria in different categories they must be classified in the most severe category. In addition, the kinetics of the } \\
\text { evolution of cumulative symptoms within } 48 \mathrm{~h} \text { predicts severe disease. } \\
\text { fPresence of } \geq 2 \text { of these criteria qualifies for an upgrade to CTCAE level } 4 \text { (very severe VOD/SOS). } \\
\text { 'Excluding pre-existent hyperbilirubinemia due to primary disease. } \\
\text { CPAP: Continuous positive airway pressure; CTCAE: Common terminology criteria for adverse event; EBMT: European Society for } \\
\text { Blood and Marrow Transplantation; GFR: Glomerular filtration rate; MOD/MOF: Multiorgan dysfunction/multiorgan failure; } \\
\text { RT: Refractory thrombocytopenia;VOD: Veno-occlusive disease/sinusoidal obstruction syndrome. } \\
\text { Adapted with permission from Corbacioglu S et al. [4] } \odot \text { as licensed under a Creative Commons Attribution NonCommercial- } \\
\text { NoDerivs } 4.0 \text { International License (2017). }\end{array}$} \\
\hline
\end{tabular}

patients, although this was accompanied by significant bleeding in 24-35\% [38-40]. The joint BCSH/BSBMT guideline does not recommend use of $\mathrm{tPA}$ for treatment of VOD/SOS due to the associated risk of bleeding [21]; guidelines from the European School of Haematology (ESH)-EBMT note that while tPA may be effective in some patients, it is contraindicated in those with MOF, hemorrhage or severe hypertension [33]. In two clinical studies in patients with VOD/SOS, administration of IV high-dose methylprednisolone $\left(500 \mathrm{mg} / \mathrm{m}^{2}\right.$ or kg every $12 \mathrm{~h}$ ) achieved response in the majority of patients, with overall Day +100 survival rates of 58\% [41] and 78\% [42]. Overall, given the associated risk of infection and limited evidence of its efficacy, this treatment option (used with commensurate caution) may be most appropriate for patients lacking therapeutic alternatives [32]. The BCSH/BSBMT guideline recommends consideration of methylprednisolone for VOD/SOS treatment, with appropriate precautionary measures for infection [21].
Clinical studies of $\mathrm{N}$-acetylcysteine have reported mixed results. A case series experience of three HSCT patients reported that administration of $\mathrm{N}$-acetylcysteine on the day after diagnosis of VOD/SOS resulted in decrease and normalization of bilirubin, as well as other liver enzymes and blood parameters [43]. However, a large trial in 160 patients following allogeneic HSCT found that $\mathrm{N}$-acetylcysteine treatment of early liver toxicity (elevated levels of bilirubin and other liver enzymes, but below the threshold of VOD/SOS diagnosis), had no effect on progression of liver toxicity and development of VOD/SOS in this population [44]. Based on this evidence, the BCSH/BSBMT guideline does not recommend routine use of $\mathrm{N}$-acetylcysteine for treatment of VOD/SOS, 'due to lack of efficacy'.

\section{- Prevention \& prophylaxis}

Reducing modifiable patient and treatment risk factors (Box 1) to the greatest extent possible is a mainstay of VOD/SOS prevention, including the use of RIC regimens, which appears 
to have reduced - but not eliminated - the incidence of VOD/SOS $[6,21,27]$. Specific conditioning measures that appear to reduce VOD/ SOS incidence include avoidance of high-risk medications such as cyclophosphamide with high-dose busulfan. It is assumed that monitoring busulfan pharmacokinetics to target a specific therapeutic window with the use of IV rather than oral busulfan and reduced dosing overall for pediatric patients might affect the incidence of VOD/SOS [6,21]. However, in one study of pediatric patients with adjusted busulfan conditioning for HSCT [45], there was a $21 \%$ (7/34) incidence of VOD/SOS, including six of seven patients aged 3-9 months with low busulfan exposure. A recent analysis from the Center for International Blood and Marrow Transplant Research (CIBMTR) also showed that use of targeted busulfan was associated with higher risk for development of VOD/ SOS compared with myeloablative dosing of busulfan without pharmacokinetic monitoring. These results raise the possibility that patients who undergo pharmacokinetic monitoring may actually be more likely to develop VOD/SOS because they are achieving higher plasma levels of busulfan [46]. In general, treatment with hepatotoxic and nephrotoxic drugs should be avoided as much as possible [17,32].

Clinical research investigating approaches to VOD/SOS prevention include at least 14 randomized controlled trials (RCTs) conducted with various therapies [21,47]. Anticoagulation therapy with heparin is among the preventive approaches that have been investigated [21]. A meta-analysis of anticoagulation therapies for prevention of VOD/SOS in patients undergoing HSCT evaluated pooled data from 12 controlled studies of heparin IV or oral, or enoxaparin treatment, including three RCTs, and did not find a statistically significant reduction in risk (pooled relative risk [RR]: 0.90; 95\% CI: 0.62-1.29) with active prophylaxis. While none of the studies reported more frequent incidence of bleeding as an adverse event (AE) in the treatment versus the control group [48], one early, noncontrolled pilot safety study ( $\mathrm{n}=28$; not included in the analysis for lack of controls) reported that $75 \%$ of the patients had to be withdrawn from treatment because of bleeding or anticipated bleeding [49]. The BCSH/BSBMT guideline states that heparin (unfractionated or low-molecular weight heparin, LMWH) is not suggested for use in VOD/ SOS prevention due to increased risk of serious bleeding [21]. The EBMT also has noted that use of heparin prophylaxis remains controversial [17].

Ursodeoxycholic acid (UA) also has been investigated for VOD/SOS prophylaxis following HSCT, although the quality of this clinical trial evidence remains controversial $[47,50]$. A 2007 systematic review found three RCTs comparing UA and standard care, and pooled results showed an RR of 0.34 (95\% CI: 0.17-0.66) for VOD/SOS when the analysis was confined to higher quality studies, although overall survival was not affected [50]. However, a 2015 Cochrane review of all preventive therapies for VOD/ SOS, including four RCTs of UA prophylaxis and 612 patients, concluded that while UA may reduce incidence of VOD/SOS (RR: 0.60; 95\% CI: $0.40-0.88 ; \mathrm{p}=0.01)$ and mortality from VOD/SOS (RR: 0.27; 95\% CI: 0.09-0.87; $\mathrm{p}=0.03$ ), the quality of RCT evidence for these end points was considered to be low (i.e., further research is likely to change the estimate) and very low (the authors are very uncertain about the estimate), respectively, based on bias of study design (e.g., lack of blinding and differences in baseline characteristics of treatment groups), and poor consistency and precision of study results [47]. Based on review of the RCT evidence, the BCSH/BSBMT guideline suggests the use of UA for prophylaxis of VOD/SOS [21]; the EBMT describes clinical data for UA as 'nonconclusive' but suggestive of beneficial effect [17]. It also should be noted that UA decreases bilirubin levels via stimulation of bile acid secretion [51], however, this reduction is of uncertain benefit to hepatic function [50]. Indeed, reduction in bilirubin levels with UA may not correspond with reduction in incidence of VOD/ SOS [52], suggesting that UA has the potential to mask this key diagnostic sign of VOD/SOS.

While various other therapies have been investigated for VOD/SOS prophylaxis, including prostaglandin E1, pentoxifylline and AT III, there are inadequate trial data, with regard to the number, size, design quality and/or magnitude of findings of the studies, available to support use of these agents for prevention of VOD/SOS $[17,21,44]$.

\section{Introduction to defibrotide}

As the only approved agent for treatment of VOD/SOS, defibrotide is acknowledged by the EBMT as 'the only proven curative treatment' for $\mathrm{VOD} / \mathrm{SOS}$, and recommended for VOD/ SOS treatment by the BCSH/BSBMT [17,21]. 
Defibrotide is a sodium salt complex mixture of oligonucleotides derived from the controlled depolymerization of porcine intestinal mucosal DNA [53]. Pharmacodynamically, defibrotide appears to act as an adenosine receptor agonist via aptameric action, and is readily bound to the plasma membranes of vascular endothelial cells [54]. The primary therapeutic actions of defibrotide in $\mathrm{VOD} / \mathrm{SOS}$ appear to include reducing endothelial cell activation and protecting endothelial cells from the prothrombotic syndrome and inflammation generated by their activation, and promoting the enzymatic action of plasmin, thus increasing fibrinolysis, restoring the thrombofibrinolytic balance and improving hepatic microvascular circulation [53-56]. More specifically, in preclinical studies, defibrotide has demonstrated mechanisms of action including increasing tPA and TM expression, and decreasing vWF and PAI-1 expression [55,57,58]; enhancing enzymatic activity of plasmin, hydrolyzing fibrin clots to soluble fibrin degradation products [55,56]; and binding to endothelial cells and protecting them from chemotherapy, TNF- $\alpha$, serum starvation, perfusion damage and oxidative stress and inflammation $[53,54,59]$. While defibrotide is thought to exert its protective effects chiefly through interaction with endothelial cell membranes, it is also internalized by endothelial cells, and further research is needed to explore possible additional actions or effects of this substance in other cell locations [53].

Further, defibrotide is antithrombotic without having significant systemic anticoagulant effects $[56,60]$, although patients should be monitored for bleeding [61-63]. In a study that looked into an association between HPSE SNPs and hepatic VOD/SOS in children undergoing allogeneic HSCT, 12 of 160 patients (8\%) were diagnosed with VOD/SOS using the modified Seattle criteria [25] and treated with defibrotide. Of those patients, ten $(83 \%)$ patients were successively treated and survived; the remaining two patients died of multiorgan dysfunction. The results of this study suggest support for an effect of defibrotide on HPSE.

The pharmacokinetics of defibrotide in humans are summarized in Table 3. At a single dose of $6.25 \mathrm{mg} / \mathrm{kg}$ administered via 2 -h infusion in healthy volunteers, defibrotide reached maximum concentration at approximately $2 \mathrm{~h}$ (at end of administration), with an approximately 40 min half-life and bioavailability (area under the plasma concentration-time curve) of $48.1 \mu \mathrm{g} / \mathrm{ml} / \mathrm{h}$ [60]. Defibrotide pharmacokinetics are generally dose-dependent [64]. Preclinical data suggest that the highest concentrations of defibrotide occur in the blood components, aorta, bone marrow, spleen, thyroid, adrenal glands and the skin, and in highly perfused organs, including the liver and kidneys, with uptake of the drug by the vascular endothelium [65]. Elimination occurs primarily via urine [65]. Defibrotide does not appear to accumulate after multiple doses in animals or in healthy or renally impaired subjects $[65,66]$ and is not cleared by hemodialysis [66]. These findings support defibrotide prescribing guidance stating no dose adjustment is necessary for hemodialysis or severe/end-stage renal disease.

\section{Clinical efficacy}

- Phase I/II trials

Phase I/II trials assessed the effect of defibrotide on $\mathrm{VOD} / \mathrm{SOS}$ in terms of complete response

Table 3. Pharmacokinetic parameters of defibrotide following one 2 -h IV infusion of $6.25 \mathrm{mg} / \mathrm{kg}$ in healthy subjects.

\begin{tabular}{|c|c|}
\hline Parameter & Value, mean $( \pm S D)$ \\
\hline$C_{\max }(\mu \mathrm{g} / \mathrm{ml})$ & $17.3(3.83)$ \\
\hline $\mathrm{t}_{\max }(\mathrm{h})$ median (min, max) & $2.0(1.0,2.0)$ \\
\hline $\operatorname{AUCt}(\mu \mathrm{g} / \mathrm{ml} \times \mathrm{h})$ & $26.9(8.53)$ \\
\hline $\mathrm{AUC}(\mu \mathrm{g} / \mathrm{ml} \times \mathrm{h})$ & $48.1(6.49)$ \\
\hline $\mathrm{Vd}(\mathrm{ml})$ & $9934(3807)$ \\
\hline $\mathrm{CL}(\mathrm{l} / \mathrm{h})$ & $10.4(1.8)$ \\
\hline Kel (I/h) & $1.25(0.7)$ \\
\hline$t_{1 / 2}$ & $0.7(0.4)$ \\
\hline \multicolumn{2}{|c|}{$\begin{array}{l}\text { AUC: Area under the plasma concentration versus time curve; AUCt: Area under the curve estimated after the test administration; } \\
\text { CL: Clearance; } C_{\text {max }}: \text { Maximum plasma concentration; IV: Intravenous; Kel: Elimination rate constant; SD: Standard deviation; } t_{\max }: \text { Time } \\
\text { to maximum plasma concentration; } \mathrm{t}_{1 / 2}: \text { Half-life; Vd: Volume of distribution. } \\
\text { Data taken from [61]. }\end{array}$} \\
\hline
\end{tabular}




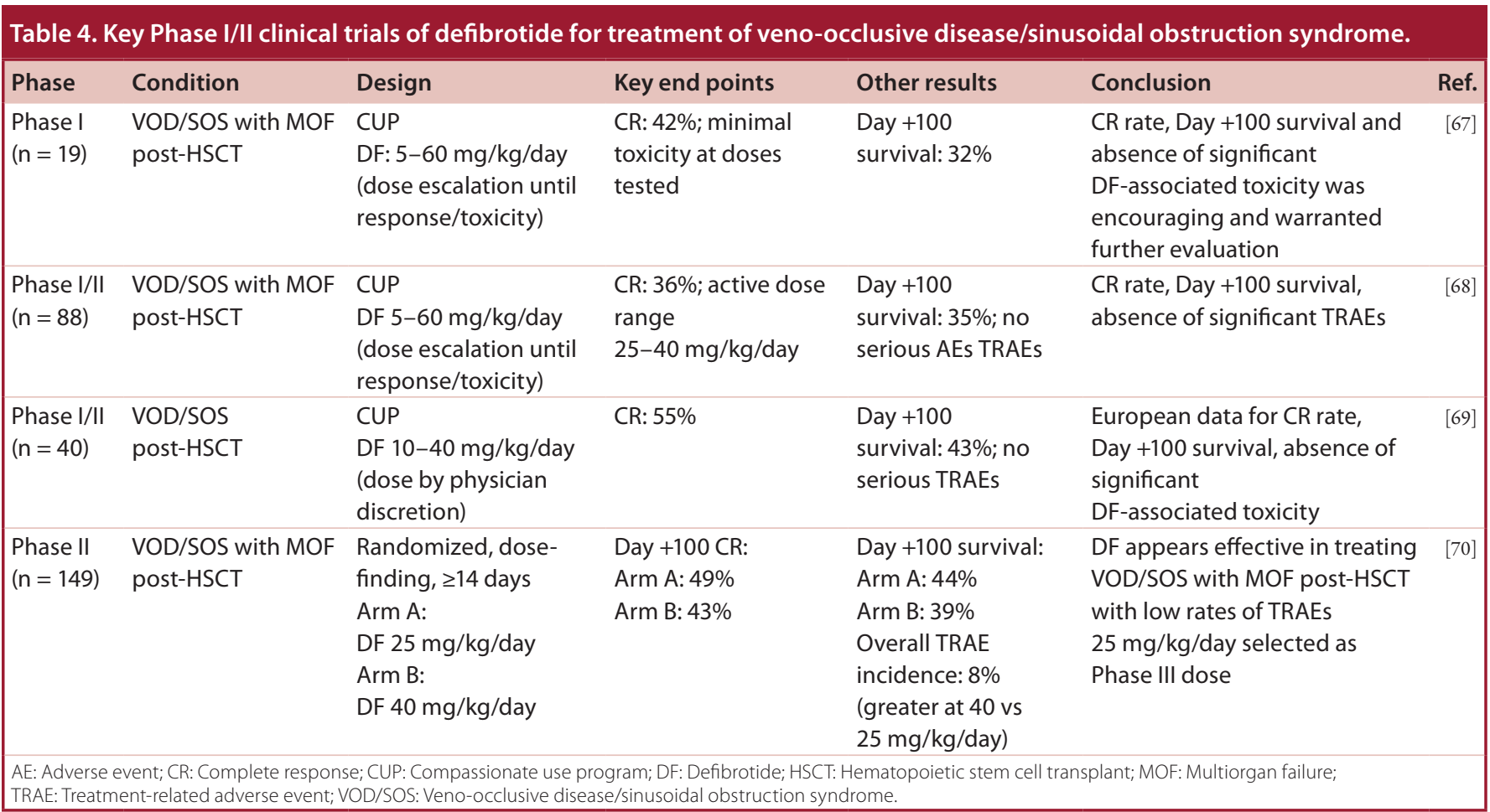

(CR), defined as reduction of bilirubin to $<2 \mathrm{mg} / \mathrm{dl}$ improvement or resolution of VOD/ SOS symptoms, and/or survival at Day +100 following HSCT (Table 4). The first evidence of defibrotide's clinical efficacy and safety was demonstrated in a Phase I study in 19 HSCT patients with VOD/SOS and MOF who received defibrotide made available for emergency compassionate use in the USA; the primary outcome was observed CR [67]. Treatment with defibrotide, dose-escalated from 5 to $60 \mathrm{mg}$ for $\geq 14$ days, resulted in CR in eight (42\%) patients and Day +100 survival in six of the responders; no severe hemorrhage was reported, and the safety data were generally favorable. Expanded US data for 88 patients treated with defibrotide given as emergency treatment for VOD/SOS with MOF, including the initial 19 patients, showed that 36\% achieved CR and 35\% were alive at Day +100 [68]. No serious toxicities including severe hemorrhage were reported.

In another study, $40 \mathrm{HSCT}$ patients were treated with defibrotide for VOD/SOS, including 26 (65\%) patients with MOF, on a compassionate-use basis at 19 European centers [69]. The daily dose varied widely, and median duration of therapy was 18 days. Retrospective data analysis for this cohort showed that CR occurred in 22 patients $(55 \%$; 95\% CI: 40-70\%) and 17 (43\%) patients (all
17 with CR) were alive at Day +100 . A smaller retrospective chart evaluation of patients who had undergone HSCT at a Turkish medical center found that 14 patients had been treated with defibrotide soon after diagnosis with VOD/SOS (six with severe disease, four moderate and four mild) [71]. Patients were treated for a median 21.5 days (range: 4-39 days). At Day +100 , CR was observed in 11 (78.6\%) patients, including three of the six patients $(50.0 \%)$ with severe disease; all patients with CR were alive at Day +100 ; the three without CR died from VOD/SOS. There were no AEs that lead to discontinuation from treatment.

Another retrospective study was conducted among 45 pediatric patients (median age: 8.2 years; range: $0.2-20$ years) who had received defibrotide treatment following diagnosis of VOD/SOS post-HSCT at 12 unselected European centers [72]. The study population included 22 (48.9\%) patients with VOD/ SOS with MOF and 23 (51.1\%) with mild-tomoderate VOD/SOS. Among all defibrotidetreated patients, 34 (75.6\%) achieved CR and 29 (64.4\%) survived beyond Day +100 ; among patients with VOD/SOS and MOF, 11 (50.0\%) had CR and eight (36.4\%) survived beyond Day +100 . A multivariate analysis of these data found that early intervention with defibrotide was the only factor that significantly correlated 
with CR. The average interval from diagnosis to treatment was 1 day in patients with $\mathrm{CR}$ compared with 5.5 days in nonresponders; average defibrotide dose was also higher in responders versus nonresponders ( $45 \mathrm{vs} 27 \mathrm{mg} / \mathrm{kg} /$ day). Regarding tolerability, defibrotide was discontinued in three $(6.7 \%)$ patients, in cases of intracranial bleeding, convulsions and diarrhea.

Following these analyses, a Phase II, randomized, multicenter, dose-finding trial was conducted in 149 adult and pediatric patients with $\mathrm{VOD} / \mathrm{SOS}$ and MOF following HSCT [70]. Adult and pediatric patients were randomized to either lower dose defibrotide $25 \mathrm{mg} / \mathrm{kg} / \mathrm{day}$ $(\mathrm{n}=75)$ or higher dose defibrotide $40 \mathrm{mg} / \mathrm{kg} /$ day $(\mathrm{n}=74)$, administered in divided doses every $6 \mathrm{~h}$ for $\geq 14$ days or until occurrence of CR, VOD/ SOS progression or unacceptable toxicity. The primary end point was $\mathrm{CR}$, defined as bilirubin $<2 \mathrm{mg} / \mathrm{dl}$ with resolution of VOD/SOSassociated MOF. Rates of CR and Day +100 survival in the total population were 46 and $42 \%$, respectively, with no significant differences between the treatment arms. The median length of treatment was 19.5 days in both dose groups. In the $25 \mathrm{mg} / \mathrm{kg} /$ day group, one patient achieved CR by day 7, 6 by day 14, 5 by day 21 , 9 by day 28 and 14 after day 29. In the $40 \mathrm{mg} /$ $\mathrm{kg} /$ day group, the corresponding numbers were two, five, zero, 13 and 10 patients. Rates of treatment-related AEs (TRAEs) were also similar between the 25 and $40 \mathrm{mg} / \mathrm{kg} /$ day treatment arms (7 vs $10 \%$, respectively; $8 \%$ overall); defibrotide-related AEs led to discontinuation in 4\% of patients overall. Rates of the most common grade 3-5 AEs were nonsignificantly lower for the 25 versus the $40 \mathrm{mg} / \mathrm{kg} /$ day dose, except for hypoxia, which was significantly lower in the $25 \mathrm{mg} / \mathrm{kg} /$ day group ( 17 vs $34 \% ; \mathrm{p}=0.025$ ). In addition, all-grade severity bleeding events were higher in the 40 versus the $25 \mathrm{mg} / \mathrm{kg} /$ day group ( 57 vs $46 \%$, respectively; nonsignificant difference). Based on the similar efficacy and slightly better safety profile for the $25 \mathrm{mg} / \mathrm{kg} /$ day dose, it was selected as the optimal dose for further evaluation in Phase III trials.

Subsequent to publication of the dose-finding study, a single-center prospective study investigated the effect of defibrotide dosing above $60 \mathrm{mg} / \mathrm{kg} /$ day and up to $110 \mathrm{mg} / \mathrm{kg} /$ day on CR and survival, in patients with VOD/SOS and MOF [73]. CR, defined as complete resolution of VOD/SOS-related symptoms and reduction of bilirubin to $\leq 2 \mathrm{mg} / \mathrm{dl}$, occurred in $55.9 \%$ of patients (95\% CI: 38-73\%), including three $(27.3 \%)$ of 11 patients who received doses $>60 \mathrm{mg} / \mathrm{kg} /$ day and Day +100 survival was 44.1\% (95\% CI: 30.2-64.4\%); however, four of five patients who received $110 \mathrm{mg} / \mathrm{kg} / \mathrm{day}$ required a $50 \%$ dose reduction, primarily due to bleeding. Therefore, no efficacy advantage was shown at the higher doses, although dosing of defibrotide up to $100 \mathrm{mg} / \mathrm{kg} / \mathrm{day}$ - well above the recommended dose $(25 \mathrm{mg} / \mathrm{kg} /$ day $)$ - did not appear to substantially increase safety risks.

In addition, data were reported from a large international compassionate use program conducted from 1998 to 2009, with participating centers in North America, Europe, Asia and the Middle East; this program was designed to provide access to defibrotide and collect outcomes [74]. Initially, the recommended dosing of IV defibrotide was a starting dose of $10 \mathrm{mg} / \mathrm{kg} /$ day with titration up to $60 \mathrm{mg} / \mathrm{kg} / \mathrm{day}$ (each daily dose in four divided doses), based on response and tolerability. However, after the Phase II dose-finding study results became available in 2004, the recommended dose became $25 \mathrm{mg} / \mathrm{kg} /$ day. The final analysis included 710 patients with VOD/SOS who received $\geq 1$ documented dose of defibrotide and had outcomes data, including 429 (60.4\%) with severe VOD/SOS as defined by Bearman criteria [75] or presence of MOF. Among all patients, the median age was 25 (range, 0.2-70) years, $43 \%$ were aged $<18$ years and the median defibrotide dose was $25 \mathrm{mg} / \mathrm{kg} /$ day. Duration of treatment, which was at investigator discretion, was a median of 15 days. Day +100 survival was $54 \%$ overall and $58 \%$ in those receiving defibrotide $25 \mathrm{mg} / \mathrm{kg} / \mathrm{day}$ (pediatric patients: $70 \%$; adult patients: $46 \%$ at $25 \mathrm{mg} / \mathrm{kg} /$ day). A total of $378(53 \%)$ patients reported one or more $\mathrm{AE}$, of which $<20 \%$ were considered at least possibly treatment-related. Since causes of deaths were generally reported as AEs, most AEs were serious $(\mathrm{n}=364)$ and fatal $(\mathrm{n}=350)$. The most common fatal AEs were MOF $(\mathrm{n}=144)$, VOD $(n=78)$ and sepsis $(n=48)$. Incidence of serious AEs was generally similar across doses.

\section{- Phase III treatment trials}

Two Phase III studies of defibrotide for treatment of VOD/SOS post-HSCT have been conducted (Table 5). A Phase III controlled trial of defibrotide treatment was conducted in 102 adults and children with VOD/SOS and advanced MOF, at 35 centers in the USA, Canada and Israel, 
compared with 32 rigorously selected, nearcontemporaneous historical-control patients treated at the study centers before the introduction of defibrotide [30]. A randomized trial design was rejected based on ethical concerns involving the high mortality risk of VOD/SOS with MOF and the substantial clinical research evidence demonstrating the efficacy of defibrotide in treatment of VOD/SOS with MOF. Because a 'gold standard' placebo controlled randomized trial was not possible, the control-group selection process was carefully conducted. Selection of historical controls involved the review of almost 7000 medical charts for patients who had recently undergone HSCT at the enrolling centers, using the same criteria as patients enrolled in the treatment arm. Further, selection utilized a medical review committee that was blinded to outcomes and made the final eligibility determination for each control patient. The primary outcome for the trial was rate of survival at Day +100 , using a propensity-adjusted analysis. Defibrotide $25 \mathrm{mg} / \mathrm{kg} / \mathrm{d}$ ay was to be administered intravenously in four divided doses for a recommended duration of $>21$ days; treatment would continue beyond 21 days if necessary to achieve resolution of VOD/SOS or until patient discharge from the hospital.

Baseline demographic and clinical characteristics, including key stratification variables, were similar in the defibrotide treatment and control groups in this trial. At Day +100 , $39(38.2 \%)$ patients in the defibrotide group were alive versus eight (25.0\%) among HCs; the estimated between-group difference was 23\% (95.1\% CI: 5.2-40.8; p = 0.0109), based on the propensity-adjusted analysis. Therefore, the number needed to treat (one/absolute risk reduction) to prevent one death was five. CR, defined by total bilirubin $<2 \mathrm{mg} / \mathrm{dl}$ and resolution of MOF, occurred in $25.5 \%$ of defibrotidetreated patients versus $12.5 \%$ of controls (19\% estimated difference between groups adjusted for propensity score; 95\% CI: 3.5-34.6; $\mathrm{p}=0.0160)$. The number needed to treat to achieve one CR was six. The median (range) time on treatment was 21.5 (1-58) days.

All but one of the defibrotide-treated patients and all control patients had $\geq 1 \mathrm{AE}$, the most common of which were hypotension $(39.2 \%$ with defibrotide, $50 \%$ HCs) and diarrhea (23.5\% defibrotide, 37.5\% HCs). Defibrotide was discontinued for a possible drug-related toxicity in $11(10.7 \%)$ patients. Incidence of common hemorrhagic AEs was similar in the defibrotide and control groups (64 and 75\%, respectively), and fatal AEs also occurred at similar rates (64 and 69\%, respectively) [30].

An additional Phase III open-label, singlearm, protocol-directed expanded access treatment (T-IND) protocol also was conducted in the USA to prospectively evaluate defibrotide for

Table 5. Phase III clinical trials of defibrotide for treatment or prophylaxis of veno-occlusive disease/sinusoidal obstruction syndrome.

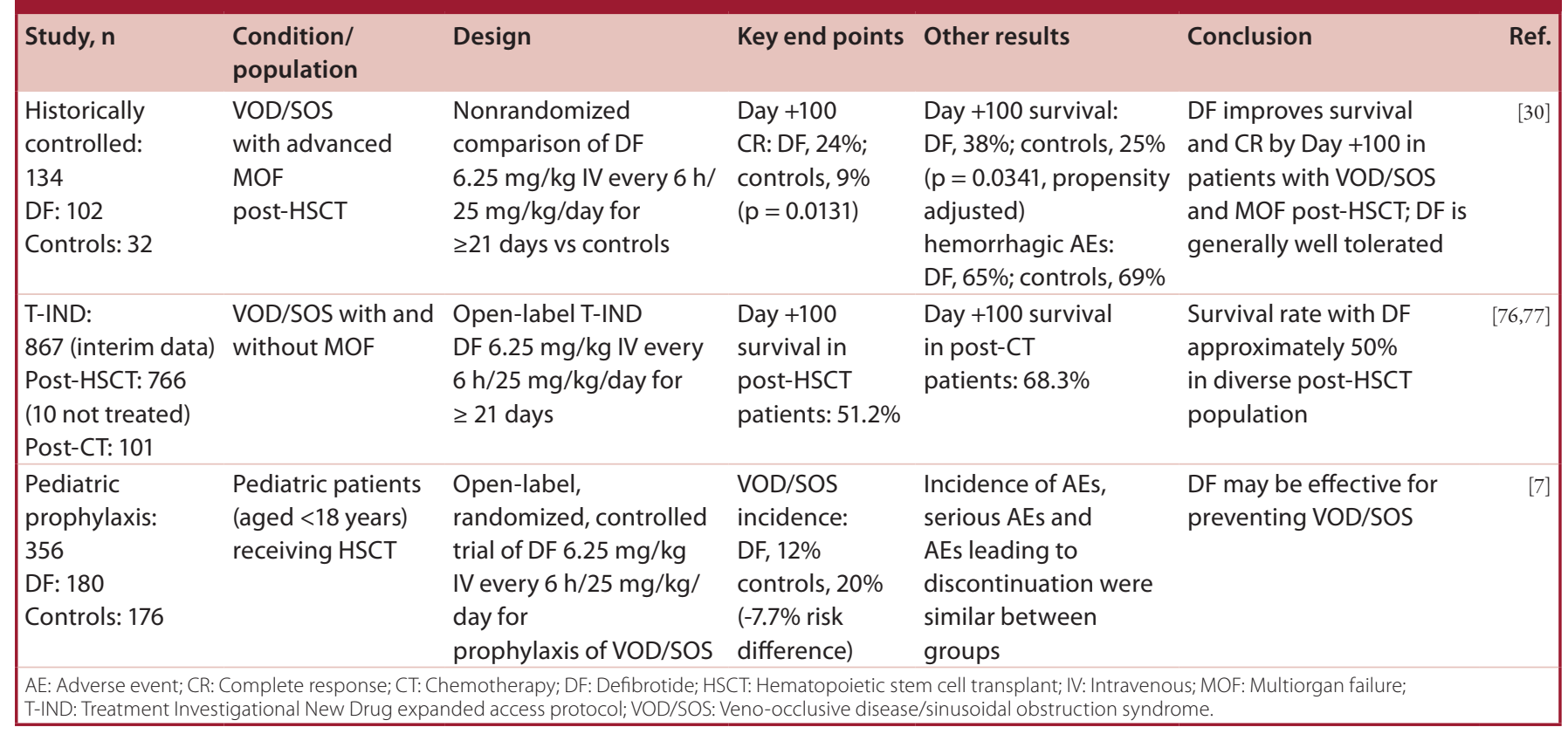


the treatment of diagnosed VOD/SOS, with and without MOF, in patients post-HSCT or postchemotherapy (i.e., without HSCT) [76] (Table 5). The protocol-recommended treatment was defibrotide $25 \mathrm{mg} / \mathrm{kg} /$ day in four divided doses, initiated as soon as possible after the patient meets eligibility requirements (diagnosis of $\mathrm{VOD} / \mathrm{SOS}$ by either Baltimore or modified Seattle criteria), and continued for a recommended $\geq 21$ days. In an interim analysis, 867 (766 post-HSCT and 101 postchemotherapy without HSCT) patients were enrolled between 14 December 2007 and 18 April 2015 [75,76]. Of the 766 postHSCT patients, 756 were diagnosed with VOD/ SOS and received $\geq 1$ dose of defibrotide. The Day +100 survival rate was $51.2 \%(387 / 756)$ in patients with or without MOF. Of the 766 post-HSCT patients, $515(67.2 \%)$ had at least one $\mathrm{AE}$, most commonly hypotension $(12.5 \%)$ and $158(20.6 \%)$ had an AE that was possibly treatment related [76]. Among the 101 postchemotherapy patients at Day $+100,69$ were alive (68.3\%); 62/101 (61.4\%) had at least one AE, most commonly diarrhea or hypotension $(7.9 \%$ each) and $22(21.8 \%)$ had an AE that was possibly treatment related [77].

Post hoc analyses also found that earlier initiation of defibrotide treatment post-VOD/ SOS diagnosis in this cohort was associated with significantly higher Day +100 survival rates for each cut-off before or after days 1, 2, 3,4 and 7 ( $\mathrm{x} \leq 0.002$, Fisher's exact test), but did not reach significance at day 14 (only $2.8 \%$ of patients started defibrotide postday 14). Survival rate differences for each cut-off ranged from 11.9 to $22.6 \%$ overall $(16.3-28.1 \%$ in patients with MOF). In a separate analysis of outcomes for 755 patients with a known day of defibrotide initiation, starting defibrotide on a specific day postdiagnosis found a trend over time significantly favoring earlier initiation $(\mathrm{p}<0.001$, Cochrane-Armitage trend test) [76]. Similar results were found for the pediatric and adult subgroups; earlier initiation of defibrotide to time of VOD/SOS diagnosis was associated with numerically higher Day +100 survival rates for all cutoffs except Day 14. Survival differences by cut-off date ranged from 11.3 to $35.6 \%$ in pediatric patients and -2.0 (Day 14) to $18.3 \%$ in adults. In both age groups, there was a significant trend over time for higher Day +100 survival with earlier initiation following diagnosis (pediatric patients: $\mathrm{p}<0.001$; adults: $\mathrm{p}=0.28)[78]$.

\section{- Phase III prevention trials}

In addition to the two Phase III treatment studies, a Phase III prophylaxis trial was conducted at 28 centers in Europe and in Israel to evaluate the efficacy and safety of defibrotide in pediatric patients for prevention of VOD/ SOS (defibrotide is not approved for this indication) [7] (Table 5). The Phase III defibrotide prophylaxis trial was an open-label, randomized, controlled study in patients aged $<18$ years $(n=356)$, who were scheduled to receive HSCT and considered at high risk of developing VOD/ SOS. Of these patients, 180 were randomized to defibrotide $25 \mathrm{mg} / \mathrm{kg} /$ day in four divided doses of $6.25 \mathrm{mg} / \mathrm{kg}$ every $6 \mathrm{~h}$, starting on the same day as the pretransplant conditioning regimen and continuing for 30 days post-HSCT, or at least $\geq 14$ days if hospital discharge occurred in $<30$ days; 176 patients were randomized to the control arm. Patients in either arm who developed VOD/SOS received defibrotide treatment.

In the primary analysis, $22(12 \%)$ patients in the defibrotide group developed VOD/SOS by 30 days post-HSCT, compared with 35 (20\%) controls (risk difference: $-7.7 \%$, 95\% CI: -15.3 to $-0.1 ; \mathrm{Z}$ test for competing risk analysis: $p=0.0488$; log-rank test: $p=0.0507)$. The tolerability and safety profile of defibrotide in this trial was manageable. Incidence of AEs (87.0 and $88.1 \%$ ), serious AEs (61.0 and 58.5\%), and AEs leading to discontinuation (9.6 and 11.9\%) were similar between defibrotide and controls, respectively. Among the 353 patients included in the safety analysis, 207 serious AEs were reported in 108 (61.0\%) patients in the defibrotide group and 231 were reported in 103 (58.5\%) controls. Cumulative hemorrhage frequency was $39 \%$ in the defibrotide group versus $37 \%$ among controls [7]. Based on the results of this trial, the $\mathrm{BCSH} / \mathrm{BSBMT}$ guideline recommended the use of defibrotide at a dose of $6.25 \mathrm{mg} / \mathrm{kg}$ IV four-times daily in children undergoing allogeneic HSCT with the following risk factors: preexisting hepatic disease; second myeloablative transplant; allogeneic transplant for leukemia beyond second relapse; conditioning with busulfan-containing regimens; prior treatment with gemtuzumab ozogamicin; and/or diagnosis of primary hemophagocytic lymphohistiocytosis, adrenoleukodystrophy or osteopetrosis [21].

Interestingly, incidence and severity of GVHD were also lower in the defibrotide group overall versus controls at Day +30 and Day +100 among patients given allogeneic HSCT $(\mathrm{p}=0.0046$ 
incidence, $\mathrm{p}=0.0034$ severity at Day +100$)[7]$. This GVHD finding was later echoed in another study that retrospectively analyzed 195 consecutive adult HSCT patients [79], which found a trend for lower incidence of acute GVHD in patients receiving defibrotide pretreatment compared with those receiving defibrotide post-HSCT and no-treatment groups (25.5 vs $40.0 \%$ and $46.5 \%$, respectively; $\mathrm{p}=0.057$ ). Grade $3 / 4$ acute GVHD did not occur in pretreated patients ( 0 vs $11.2 \%$ and $15.5 \%$, respectively; $\mathrm{p}=0.051$ ) [79].

Currently, a Phase III, randomized, adaptive, multicenter study to evaluate the efficacy, safety and tolerability of defibrotide prophylaxis versus best supportive care for prevention of VOD/SOS in adult and pediatric patients who are undergoing HSCT and are at high or very high risk for VOD/SOS (Harmony; NCT02851407) is underway [80]. Randomization is stratified via an interactive web response system by high- or very high-risk category for developing VOD/SOS (diagnosed using modified Seattle criteria with a $>5 \%$ weight-gain threshold), age $>16$ years or $\leq 16$ years and country. Defibrotide prophylaxis is administered at a dose of $25 \mathrm{mg} / \mathrm{kg} /$ day in four divided doses of $6.25 \mathrm{mg} / \mathrm{kg}$ given via $2-\mathrm{h} \mathrm{IV}$ infusion every $6 \mathrm{~h}$ for a recommended minimum of 21 days, ending no later than Day +30 postHSCT. The primary efficacy assessment is VOD/ SOS-free survival by Day +30 post-HSCT.

\section{Safety \& tolerability summary}

Key safety outcomes in defibrotide trials are provided in Table 6 \& 7. Overall, the incidence of defibrotide TRAEs was found to be $6 \%$ in a 2013 drug safety evaluation of defibrotide, which reviewed data for 1824 pediatric and adult HSCT patients who had received defibrotide for treatment or prophylaxis of VOD/ SOS $[63,81]$. As expected, the rate of AEs assessed as at least possibly defibrotide related was highest in patients with VOD/SOS and MOF, associated with illness and comorbidities, and lowest in those receiving defibrotide prophylaxis. The most common AEs of any type or etiology reported across defibrotide studies were hemorrhage, hypotension and gastrointestinal disturbances, including diarrhea, vomiting and nausea. Importantly, reported types and rates of AEs occurring among defibrotide-treated patients were similar to those in controls in the Phase III historically controlled study [30], and in the pediatric Phase III prophylaxis study [7]. These data suggest that the AEs may not be primarily related to defibrotide treatment but often arose from complications of HSCT.

\section{Regulatory affairs}

In March 2016, defibrotide was approved by the US FDA for the treatment of adult and pediatric patients with hepatic VOD/SOS with renal or pulmonary dysfunction following HSCT [62]. Defibrotide was previously approved in the EU for treatment of severe hepatic VOD/SOS postHSCT in adults and in children aged older than 1 month [61]. Prescribing guidelines in both regions specify a defibrotide dose of $25 \mathrm{mg} / \mathrm{kg} /$ day in four divided infusions every $6 \mathrm{~h}$. Defibrotide is not approved anywhere for prophylaxis of VOD/SOS.

\section{Conclusion}

Defibrotide has demonstrated significant clinical efficacy for the treatment of VOD/SOS in terms of improved survival and CR rates in patients with VOD/SOS and MOF, and earlier defibrotide treatment after $\mathrm{VOD} / \mathrm{SOS}$ diagnosis is associated with more favorable outcomes. The safety profile for defibrotide includes hemorrhage, hypotension and gastrointestinal disturbances; however, types and rates of AEs in patients receiving defibrotide are similar to those recorded in control patients. Clinical data also appear to support the efficacy of defibrotide in treatment of VOD/SOS without MOF and in prevention of VOD/SOS, although defibrotide is not indicated for these uses and further research data are needed. Indeed, as prompt initiation of defibrotide was associated with superior treatment outcomes, future research should focus on the identification of blood biomarkers and dynamic clinical parameters in the days prior to $\mathrm{VOD} / \mathrm{SOS}$ onset that would promote earlier diagnosis and treatment. Additional future investigations might aim at optimizing VOD/ SOS treatment strategies, including therapeutic combinations with defibrotide and development of an oral formulation to allow easier access and shorten inpatient admission. Defibrotide should also be investigated for its potential benefit in the treatment and/or prevention of other conditions associated with endothelial injury after HSCT, including thrombotic microangiopathy and GVHD. Moreover, the emergence of the first effective therapy for VOD/SOS has re-energized research into the pathophysiology and clinical characteristics of VOD/SOS, which is already helping to reduce its risks and improve its recognition and management. 
Table 6. Safety/tolerability data for defibrotide in Phase III clinical studies.

\begin{tabular}{|c|c|c|}
\hline Study safety population & Most common AEs (\%) & Ref. \\
\hline $\begin{array}{l}\text { Historically controlled: } \\
\text { - DF vs control trial } \\
\text { - } \mathrm{n}=134 \\
\text { - DF: } 102 \\
\text { - Controls: } 32\end{array}$ & $\begin{array}{l}\text { Total: DF (100.0); controls (96.9) } \\
\text { Hypotension: DF (39.2); controls (50) } \\
\text { Diarrhea: DF (23.5); controls ( } 37.5) \\
\text { Vomiting: DF (19.6); controls (25.0) } \\
\text { Pyrexia: DF (13.7); controls (28.1) } \\
\text { Treatment-related: } \\
\text { Most commonly hypotension and hemorrhage }\end{array}$ & [30] \\
\hline $\begin{array}{l}\text { T-IND: } \\
-\mathrm{n}=867 \text { (interim data) } \\
\text { - Post-HSCT: } 766 \\
\text { - Post-CT: } 101\end{array}$ & $\begin{array}{l}\text { Total: } 577 \text { (66.6\%) } \\
\text { Hypotension (12.5) } \text { MOF }^{\dagger}(11.0) \\
\text { VOD/SOS }^{\dagger}(8.1) \\
\text { Respiratory failure } \\
\text { Diarrhea (6.8) } \\
\text { Pulmonary hemorrhage (6.7) } \\
\text { Pyrexia (6.6) } \\
\text { Renal failure }{ }^{\dagger}(6.1) \\
\text { Treatment-related: } \\
\text { Post-HSCT: } 158(20.6 \%) \\
\text { Postchemotherapy: } 22(21.8 \%)\end{array}$ & {$[76]$} \\
\hline $\begin{array}{l}\text { Pediatric prophylaxis: } \\
-\mathrm{n}=353 \\
\text { - DF: } 177 \\
\text { - Controls: } 176^{\ddagger}\end{array}$ & $\begin{array}{l}\text { Total: DF (87.0\%); controls (88.1\%) } \\
\text { Hemorrhage: DF (22); controls ( } 21) \\
\text { Treatment-related: } \\
\text { DF (6); controls (4) } \\
\text { Leading to discontinuation: DF (9.6); controls (11.9) }\end{array}$ & [7] \\
\hline \multicolumn{3}{|c|}{$\begin{array}{l}{ }^{+} \text {AEs related to VOD/SOS, MOF and HSCT not reported unless considered serious. } \\
\text { FIn the control (no prophylaxis) arm, } 36 \text { patients received defibrotide for treatment of VOD/SOS. } \\
\text { DF: Defibrotide; HSCT: Hematopoietic stem cell transplant; MOF: Multiorgan failure; T-IND: Treatment Investigational New Drug } \\
\text { expanded access protocol; VOD/SOS: Veno-occlusive disease/sinusoidal obstruction syndrome. }\end{array}$} \\
\hline
\end{tabular}

Table 7. Key defibrotide safety characteristics versus alternative therapies ${ }^{\dagger}$ for veno-occlusive disease/sinusoidal obstruction syndrome with multiorgan failure.

\begin{tabular}{|c|c|c|c|c|}
\hline Characteristic & Defibrotide & $\begin{array}{l}\text { tPA/heparin } \\
\text { (off-label use) }\end{array}$ & $\begin{array}{l}\text { Methylprednisolone } \\
\text { (off-label use) }\end{array}$ & $\begin{array}{l}\mathrm{N} \text {-acetylcysteine }{ }^{\ddagger} \\
\text { (off-label use) }\end{array}$ \\
\hline Hemorrhage & $\begin{array}{l}\text { Deaths due to } \\
\text { bleeding in up to } 15 \% \\
\text { patients }\end{array}$ & $\begin{array}{l}\text { Rates of grade } 3 / 4 \\
\text { bleeding }(\sim 24-35 \%)\end{array}$ & $\begin{array}{l}\text { No increased risk of } \\
\text { grade } 3 / 4 \text { bleeding }\end{array}$ & $\begin{array}{l}\text { No increased } \\
\text { risk of grade } 3 / 4 \\
\text { bleeding }\end{array}$ \\
\hline Fatal AEs & $\begin{array}{l}\text { Defibrotide: } 64 \% \\
\text { Historical } \\
\text { controls: } 69 \%\end{array}$ & $\begin{array}{l}\text { Deaths due to } \\
\text { bleeding in up to } \\
18 \% \text { patients }\end{array}$ & Low risk & Low risk \\
\hline Serious AEs & $\begin{array}{l}\text { Generally } \\
\text { hemorrhage }\end{array}$ & $\begin{array}{l}\text { Generally } \\
\text { hemorrhage }\end{array}$ & $\begin{array}{l}\text { High risk of fungal } \\
\text { infection ( } 31 \%) \text { or } \\
\text { sepsis }(45 \%)\end{array}$ & $\begin{array}{l}\text { Low rates of AEs } \\
\text { reported }\end{array}$ \\
\hline \multicolumn{5}{|c|}{$\begin{array}{l}\text { 'Medical therapies beyond standard supportive care (i.e., maintenance of fluid balance, renal replacement, ventilator support, } \\
\text { transjugular intrahepatic portosystemic shunt). } \\
\text { "No clinical evidence of efficacy. } \\
\text { AE: Adverse event; MOF: Multiorgan failure; VOD/SOS: Veno-occlusive disease/sinusoidal obstruction syndrome. } \\
\text { Data taken from }[21,30,38-42,44,63]\end{array}$} \\
\hline
\end{tabular}




\section{EXECUTIVE SUMMARY}

\section{Background}

- Hepatic veno-occlusive disease/sinusoidal obstruction syndrome (VOD/SOS) is an unpredictable and potentially lifethreatening complication of conditioning regimens for hematopoietic stem cell transplant (HSCT).

- VOD/SOS occurs in an estimated $13.7 \%$ of post-HSCT patients; incidence is lower after reduced intensity conditioning allogeneic HSCT and autologous HSCT.

- VOD/SOS with multiorgan failure (MOF) may be associated with $>80 \%$ mortality.

- $\mathrm{VOD} / \mathrm{SOS}$ begins with toxic injury to sinusoidal endothelial cells and is characterized by a prothrombotichypofibrinolytic state.

\section{Overview of VOD/SOS treatment}

- Traditionally, safe and effective treatments for VOD/SOS have been lacking, representing an unmet medical need.

- Defibrotide is now approved for treatment of post-HSCT hepatic VOD/SOS that is severe/with renal or pulmonary dysfunction and is available in the EU and the USA (see 'Regulatory Affairs').

\section{Introduction to defibrotide}

- Defibrotide is a sodium salt complex mixture of oligonucleotides derived from the controlled depolymerization of porcine intestinal mucosal DNA.

- Preclinical data suggest that defibrotide may act by reducing endothelial-cell activation, protecting endothelial cells and restoring thrombofibrinolytic balance.

- Defibrotide is antithrombotic without significant anticoagulant effects and with actions restricted to the microvasculature, thus reducing its associated risk of bleeding.

- Defibrotide (6.25 mg/kg administered via four 2-h infusions) in healthy volunteers reached maximum concentration at $2 \mathrm{~h}$; defibrotide does not appear to accumulate after multiple doses in healthy or renally impaired subjects or to be cleared by hemodialysis.

\section{Clinical efficacy}

- In Phase I/II clinical trials in patients with VOD/SOS, including many with MOF, defibrotide demonstrated rates of complete response and survival at Day +100 post-HSCT of approximately $35-79 \%$, with generally similar rates for both outcomes.

- A Phase II, dose-finding study identified $25 \mathrm{mg} / \mathrm{kg} /$ day as the optimal dose for Phase III evaluation, based on its safety profile compared with a $40 \mathrm{mg} / \mathrm{kg} /$ day dose.

- In a historically controlled, multicenter, international Phase III trial in 102 adults and children with VOD/SOS and advanced MOF, versus a rigorously selected control group, defibrotide ( $25 \mathrm{mg} / \mathrm{kg} /$ day in four divided doses) was associated with $38.2 \%$ survival versus $25 \%$ for controls at Day +100 post-HSCT; propensity-adjusted between-group difference was $23 \%(p=0.0109)$.

- In a Phase III, protocol-directed, expanded access program Day +100 survival rates in 642 defibrotide-treated patients post-HSCT or chemotherapy, with VOD/SOS with and without MOF, were $52.5 \%$ overall and $47.3 \%$ in patients with MOF $(n=387)$.

- Defibrotide also demonstrated efficacy in a Phase III trial (although with marginal statistical significance) as prophylaxis for VOD/SOS in children.

\section{Postmarketing surveillance}

- Not available.

\section{Safety \& tolerability}

- An analysis of pooled data for 1824 defibrotide-treated adult and pediatric patients found that the incidence of treatment-related adverse events (AEs) was $6 \%$. 


\section{EXECUTIVE SUMMARY (CONT.)}

- The most common AEs reported with defibrotide across studies include hemorrhage, hypotension and gastrointestinal disturbances, such as diarrhea, vomiting and nausea.

- Incidence of AEs has been similar between defibrotide-treated patients and controls in Phase III trials; these similar rates suggest that most of the AEs reported in these trials were related to complications of HSCT rather than to defibrotide treatment.

\section{Regulatory affairs}

- Defibrotide was recently approved for treatment of hepatic VOD/SOS with renal or pulmonary dysfunction following HSCT in the USA and for treatment of post-HSCT patients with severe hepatic VOD/SOS in the EU.

Financial \& competing interests disclosure

$P$ Richardson has served on advisory committees and as a consultant for Gentium SpA/Jazz Pharmaceuticals. S Grupp has served on advisory committees and as a consultant to Jazz Pharmaceuticals. A Pagliuca has served on advisory boards and the speakers bureau for and received honoraria from Gentium. A Krishnan and VT Ho have served as consultants to Jazz Pharmaceuticals. S Corbacioglu has served as a consultant for and received honoraria from Gentium and served as a consultant for Jazz Pharmaceuticals. The authors have no other relevant affiliations or financial involvement with any organization or entity with a financial interest in or financial conflict with the subject matter or materials discussed in the manuscript apart from those disclosed.
The authors thank $L$ Deblinger of The Curry Rockefeller Group, LLC, Tarrytown, NY, USA, for providing medical writing support, and The Curry Rockefeller Group for editorial support in formatting, proofreading, copy editing and fact checking, which was funded by Jazz Pharmaceuticals in accordance with Good Publication Practice (GPP3) guidelines [82]. Jazz Pharmaceuticals also reviewed and edited the manuscript for scientific accuracy. Although Jazz Pharmaceuticals was involved in the topic concept and fact checking of information, the content of this manuscript, the ultimate interpretation, and the decision to submit it for publication in International Journal of Hematologic Oncology was made independently by the authors.

\section{References}

Papers of special note have been highlighted as:

- of interest; $\bullet \bullet$ of considerable interest

1 Fan-CQ, Crawford JM. Sinusoidal obstruction syndrome (hepatic venoocclusive disease). J. Clin. Exp. Hepatol. 4(4), 332-346 (2014).

2 Helmy A. Review article: updates in the pathogenesis and therapy of hepatic sinusoidal obstruction syndrome. Aliment Pharmacol. Ther. 23(1), 11-25 (2006).

3 DeLeve LD, Shulman HM, McDonald GB. Toxic injury to hepatic sinusoids: sinusoidal obstruction syndrome (veno-occlusive disease). Semin. Liver Dis. 22(1), 27-41 (2002).

4 Corbacioglu S,Carreras E, Ansari M et al., Diagnosis and severity criteria for sinusoidal obstruction syndrome/veno-occlusive disease in pediatric patients: a new classification from the European Society for Blood and Marrow Transplantation (EBMT). Bone Marrow Transplant. (2017) (In Press).

- New European Society for Blood and Marrow Transplantation diagnostic and severity criteria for veno-occlusive disease/ sinusoidal obstruction syndrome
(VOD/SOS), which are specifically for pediatric patients - these guidelines differ in some respects from those for adults.

5 Coppell JA, Richardson PG, Soiffer R et al. Hepatic veno-occlusive disease following stem cell transplantation: incidence, clinical course, and outcome. Biol. Blood Marrow Transplant. 16(2), 157-168 (2010).

- Reviews incidence of VOD/SOS and mortality data from 135 studies.

6 Carreras E, Díaz-Beyá M, Rosiñol L et al. The incidence of veno-occlusive disease following allogeneic hematopoietic stem cell transplantation has diminished and the outcome improved over the last decade. Biol. Blood Marrow Transplant. 17(11), 1713-1720 (2011).

- This largest post-transplant VOD case series from a single institution showed that the decline in VOD incidence was significantly associated with the introduction of reduced intensity conditioning and defibrotide.

7 Corbacioglu S, Cesaro S, Faraci M et al. Defibrotide for prophylaxis of hepatic veno-occlusive disease in paediatric haemopoietic stem-cell transplantation: an open-label, phase 3, randomized controlled trial. Lancet 379 (9823), 1301-1309 (2012).

- This is the largest prospective, controlled study of defibrotide prophylaxis in pediatric patients who underwent hematopoietic stem cell transplantation (HSCT) to date.

8 Barker CC, Butzner JD, Anderson RA, Brant $\mathrm{R}$, Sauve RS. Incidence, survival and risk factors for the development of veno-occlusive disease in pediatric hematopoietic stem cell transplant recipients. Bone Marrow Transplant. 32(1), 79-87 (2003).

9 Cesaro S, Pillon M, Talenti E et al. A prospective survey on incidence, risk factors and therapy of hepatic veno-occlusive disease in children after hematopoietic stem cell transplantation. Haematologica 90 (10), 1396-1404 (2005).

10 Lucarelli G, Clift RA, Galimberti M et al. Marrow transplantation for patients with thalassemia: results in class 3 patients. Blood 87(5), 2082-2088 (1996).

11 Corbacioglu S, Honig M, Lahr G et al. Stem cell transplantation in children with infantile osteopetrosis is associated with a high incidence of VOD, which could be prevented with defibrotide. Bone Marrow Transplant. 38(8), 547-553 (2006). 
12 Ouachee-Chardin M, Elie C, de Saint Basile Get al. Hematopoietic stem cell transplantation in hemophagocytic lymphohistiocytosis: a single-center report of 48 patients. Pediatrics 117(4), E743-E750 (2006).

13 Naples J, Skeens M, Bajwa R. Anicteric hepatic veno-occlusive disease after hematopoietic stem cell transplantation in children. Blood 124(21), 5849 (2014).

14 Myers KC, Dandoy C, El-Bietar J, Davies $\mathrm{SM}$, Jodele $\mathrm{S}$. Veno-occlusive disease of the liver in the absence of elevation in bilirubin in pediatric patients after hematopoietic stem cell transplantation. Biol. Blood Marrow Transplant. 21(2), 379-381 (2015).

15 Carreras E, Diaz-Ricart M. The role of the endothelium in the short-term complications of hematopoietic SCT. Bone Marrow Transplant. 46(12), 1495-1502 (2011).

16 Bearman SI. The syndrome of hepatic veno-occlusive disease after marrow transplantation. Blood 85(11), 3005-3020 (1995).

- Describes the clinical syndrome of VOD and discusses the importance of diagnosing and managing VOD early.

17 Mohty M, Malard F, Abecassis M et al. Sinusoidal obstruction syndrome/ veno-occlusive disease: current situation and perspectives - a position statement from the European Society for Blood and Marrow Transplantation (EBMT). Bone Marrow Transplant. 50 (6), 781-789 (2015).

- Pathophysiology, risk factors, diagnosis criteria, biomarkers and treatments of VOD are highlighted.

18 DeLeve LD, McCuskey RS, Wang X et al. Characterization of a reproducible rat model of hepatic veno-occlusive disease. Hepatology 29(6), 1779-1791 (1999).

19 McDonald G, Hinds MS, Fisher LD et al. Veno-occlusive disease of the liver and multiorgan failure after bone marrow transplantation: a cohort study of 355 patients. Ann. Intern. Med. 118(4), 255-267 (1993).

- Defines the modified Seattle criteria, demonstrated several pre- and post-transplant risk factors are associated with hepatic VOD.

20 Jones RJ, Lee KS, Beschorner WE et al. Venoocclusive disease of the liver following bone marrow transplantation.

Transplantation 44(6), 778-783 (1987).

- Presents the Baltimore criteria describing the clinical features and high mortality associated with hepatic VOD following bone marrow transplantation.
21 Dignan FL, Wynn RF, Hadzic N, et al. Haemato-oncology Task Force of the British Committee for Standards in Haematology and the British Society for Blood and Marrow Transplantation. BCSH/BSBMT guideline: diagnosis and management of veno-occlusive disease (sinusoidal obstruction syndrome) following haematopoietic stem cell transplantation. Br. J. Haematol. 163(4), 444-457 (2013).

- Includes recommendations for prophylaxis and treatment of hepatic VOD in both adult and pediatric patients undergoing HSCT.

22 Mohty M, Malard F, Abecassis M et al. Revised diagnosis and severity criteria for sinusoidal obstruction syndrome/venoocclusive disease in adult patients: a new classification from the European Society for Blood and Marrow Transplantation. Bone Marrow Transplant. 51(7), 906-912 (2016).

- An essential update of diagnosis and severity criteria for VOD/SOS, with important implications for management of VOD/SOS, based on changes in patient populations receiving HSCT that influence the natural history of VOD/SOS, and increased/improved data on the variability of VOD/SOS clinical signs, symptoms and progression.

23 Lee JL, Gooley T, Bensinger W, Schiffman K, McDonald GB. Veno-occlusive disease of the liver after busulfan, melphalan, and thiotepa conditioning therapy: incidence, risk factors, and outcome. Biol. Blood Marrow Transplant. 5(5), 306-315 (1999).

24 Carreras E, Rosinol L, Terol MJ et al. Veno-occlusive disease of the liver after high-dose cytoreductive therapy with busulfan and melphalan for autologous blood stem cell transplantation in multiple myeloma patients. Biol. Blood Marrow Transplant. 13(12), 1448-1454 (2007)

25 Gruhn B, Wittig S, Arndt C, Seifert C. Heparanase polymorphisms: influence on incidence of hepatic sinusoidal obstruction syndrome in children undergoing allogeneic hematopoietic stem cell transplantation. Blood 124(21), 3886 (2014).

26 Dalle JH, Giralt SA. Hepatic veno-occlusive disease after hematopoietic stem cell transplantation: risk factors and stratification, prophylaxis, and treatment. Biol. Blood Marrow Transplant. 22(3), 400-409 (2016).

27 Tsirigotis PD, Resnick IB, Avni B et al. Incidence and risk factors for moderate-tosevere veno-occlusive disease of the liver after allogeneic stem cell transplantation using a reduced intensity conditioning regimen. Bone Marrow Transplant. 49(11), 1389-1392 (2014).
28 Yakushijin K, Atsuta Y, Doki N et al. Sinusoidal obstruction syndrome after allogeneic hematopoietic stem cell transplantation: incidence, risk factors and outcomes. Bone Marrow Transplant. 51(3), 403-409 (2016).

29 Strouse C, Richardson P, Prentice G et al. Defibrotide for treatment of severe veno-occlusive disease in pediatrics and adults: an exploratory analysis using data from the Center for International Blood and Marrow Transplant Research. Biol. Blood Marrow Transplant. 22(7), 1306-1302 (2016).

30 Richardson P, Riches ML, Kernan NA et al. Phase 3 trial of defibrotide for the treatment of severe veno-occlusive disease and multi-organ failure. Blood 127(13), 1656-1665 (2016).

-• Demonstrated the efficacy and tolerability of defibrotide in patients with post-transplant hepatic VOD and multiorgan failure, with significant improvement in survival and complete response at Day +100 compared with the historical cohort.

31 Cheuk DK, Wang P, Lee TL et al. Risk factors and mortality predictors of hepatic veno-occlusive disease after pediatric hematopoietic stem cell transplantation. Bone Marrow Transplant. 40 (10), 935-944 (2007).

32 Carreras E. How I manage sinusoidal obstruction syndrome after haematopoietic cell transplantation. Br. J. Haematol. 168(4), 481-91 (2015).

33 Carreras E. Early complications after HSCT. In: The EBMT Handbook: Haematopoietic Stem Cell Transplantation (6th Edition). Apperley J, Carreras E, Gluckman E, Masszi T (Eds). EBMT-ESH, Geneva, Switzerland (2012).

- Chapter 11 describes the clinical features and treatment of VOD and other early complications of HSCT.

34 Campos-Varela I, Castells L, Dopazo C et al. Transjugular intrahepatic portosystemic shunt for the treatment of sinusoidal obstruction syndrome in a liver transplant recipient and review of the literature. Liver Transpl. 18(2), 201-205 (2012).

35 Smith FO, Johnson MS, Scherer LR et al. Transjugular intrahepatic portosystemic shunting (TIPS) for treatment of severe hepatic veno-occlusive disease. Bone Marrow Transplant. 18(3), 643-646 (1996).

36 Zenz T, Rossle M, Bertz H, Siegerstetter V, Ochs A, Finke J. Severe veno-occlusive disease after allogeneic bone marrow or peripheral stem cell transplantation - role of 
tranjugular intrahepatic portosystemic shunt (TIPS). Liver 21(1), 31-36 (2001).

37 Schoppmeyer K, Lange T, Wittekind C et al. TIPS for veno-occlusive disease following stem cell transplantation. $Z$ Gastroenterol. 44(6), 483-486 (2006)

38 Bearman SI, Lee JL, Baron AE et al. Treatment of hepatic venocclusive disease with recombinant human tissue plasminogen activator and heparin in 42 marrow transplant patients. Blood 89(5), 1501-1506 (1997).

39 Schriber J, Milk B, Shaw D et al. Tissue plasminogen activator (tPA) as therapy for hepatotoxicity following bone marrow transplantation. Bone Marrow Transplant. 24(12), 1311-1314 (1999).

40 Yoon JH, Min WS, Kim HJ et al. Experiences of t-PA use in moderate-to-severe hepatic veno-occlusive disease after hematopoietic SCT: is it still reasonable to use t-PA? Bone Marrow Transplant. 48(12), 1562-1568 (2013).

41 Al Beihany A, Al Omar H, Sahovic E et al. Successful treatment of hepatic venoocclusive disease after myeloablative allogeneic hematopoietic stem cell transplantation by early administration of a short course of methylprednisolone. Bone Marrow Transplant. 41(3), 287-291 (2008).

42 Myers KC, Lawrence J, Marsh RA et al. High-dose methylprednisolone for veno-occlusive disease of the liver in pediatric hematopoietic stem cell transplantation recipients. Biol. Blood Marrow Transplant. 19(3), 500-503 (2013).

43 Ringdén O, Remberger M, Lehmann $\mathrm{S}$ et al. $\mathrm{N}$-acetylcysteine for hepatic veno-occlusive disease after allogeneic stem cell transplantation. Bone Marrow Transplant. 25(9), 993-996 (2000).

44 Barkholt L, Remberger M, Hassan Z et al. A prospective randomized study using $\mathrm{N}$-acetyl-L-cysteine for early liver toxicity after allogeneic hematopoietic stem cell transplantation. Bone Marrow Transplant. 41(9), 785-790 (2008).

45 Malär R, Sjöö F, Rentsch K, Hassan M, Güngör $T$. Therapeutic drug monitoring is essential for intravenous busulfan therapy in pediatric hematopoietic stem cell recipients. Pediatr. Transplant. 15(6), 580-588 (2011).

46 Strouse C, Zhang Y, Zhang MJ et al. Stratification of allogeneic hematopoietic cell transplant by risk of developing veno-occlusive disease: a model for assigning a risk score. Blood 128(22), 983 (2016).
47 Cheuk DK, Chiang AK, Ha SY, Chan GC. Interventions for prophylaxis of hepatic veno-occlusive disease in people undergoing haematopoietic stem cell transplantation. Cochrane Database Syst. Rev. 5, CD009311 (2015).

48 Imran H, Tleyjeh IM, Zirakzadeh A et al. Use of prophylactic anticoagulation and the risk of hepatic veno-occlusive disease in patients undergoing hematopoietic stem cell transplantation: a systematic review and meta-analysis. Bone Marrow Transplant. 37(7), 677-686 (2006).

49 Bearman SI, Hinds MS, Wolford JL et al. A pilot study of continuous infusion heparin for the prevention of hepatic veno-occlusive disease after bone marrow transplantation. Bone Marrow Transplant. 5(6), 407-411 (1990).

50 Tay J, Tinmouth A, Fergusson D et al. Systematic review of controlled clinical trials on the use of ursodeoxycholic acid for the prevention of hepatic veno-occlusive disease in hematopoietic stem cell transplantation. Biol. Blood Marrow Transplant. 13(2), 206-217 (2007).

51 Tsochatzis EA, Feudjo M, Rigamonti C, Vlachogiannakos J, Carpenter JR, Burroughs AK. Ursodeoxycholic acid improves bilirubin but not albumin in primary biliary cirrhosis: further evidence for nonefficacy. Biomed. Res. Int. 2013, 139763 (2013).

52 Ruutu T, Eriksson B, Remes K et al. Ursodeoxycholic acid for the prevention of hepatic complications in allogeneic stem cell transplantation. Blood 100 (6), 1977-1983 (2002).

53 Pescador R, Capuzzi L, Mantovani M et al. Defibrotide: properties and clinical use of an old/new drug. Vascular Pharmacol. 59(1-2), 1-10 (2013).

- Reviews the more important experimental and clinical studies of defibrotide.

54 Palomo M, Mir E, Rovira M, Escolar G, Carreras E, Diaz-Ricart M. What is going on between defibrotide and endothelial cells? Snapshots reveal the hot spots of their romance. Blood 127(13), 1719-1727 (2016).

55 Echart CL, Graziadio B, Somaini S et al. The fibrinolytic mechanism of defibrotide: effect of defibrotide on plasmin activity. Blood Coagul. Fibrinolysis 20 (8), 627-634 (2009).

56 Falanga A, Vignoli A, Marchetti M, Barbui T. Defibrotide reduces procoagulant activity and increases fibrinolytic properties of endothelial cells. Leukemia 17(8), 1636-1642 (2003).

57 Nunziata A, Mariani MF, Cascone $M$ et al. Increased plasma t-PA activity and urinary
PGE2 after repeated oral administration of defibrotide to the rat and the mouse. Thromb. Res. 64(2), 279-284 (1991).

58 Palomo M, Diaz-Ricart M, Rovira M et al. Defibrotide prevents the activation of macrovascular and microvascular endothelia caused by soluble factors released to blood by autologous hematopoietic stem cell transplantation. Biol. Blood Marrow Transplant. 17(4), 497-506 (2011).

59 Schröder H. Defibrotide protects endothelial cells, but not L929 tumour cells, from tumour necrosis factor-alpha-mediated cytotoxicity. J. Pharm. Pharmacol. 47(3), 250-252 (1995).

60 Benimetskaya L, Wu S, Voskresenskiy AM et al. Angiogenesis alteration by defibrotide: implications for its mechanism of action in severe hepatic veno-occlusive disease. Blood 112(10), 4343-4352 (2008).

61 Defitelio $^{\circledR}$ (defibrotide). Summary of product characteristics (2016). www.ema.europa.eu/ema/

62 Defitelio $^{\circledR}$ (defibrotide sodium), prescribing information. Jazz Pharmaceuticals, Inc., CA, USA (2016).

63 Richardson PG, Corbacioglu S, Ho VT et al. Drug safety evaluation of defibrotide. Expert Opin. Drug Saf. 12(1), 123-136 (2013).

- Demonstrated that defibrotide was well tolerated in a majority of the studies, with the most common adverse events such as hemorrhage, hypotension, nausea and vomiting being mostly mild or moderate in nature.

64 Noseda G, Fragiacomo C, Ferrari D. Pharmacokinetics of defibrotide in healthy volunteers. Haemostasis 16(Suppl. 1), 26-30 (1986).

65 Palmer KJ, Goa KL. Defibrotide: a review of its pharmacodynamic and pharmacokinetic properties, and therapeutic use in vascular disorders. Drugs 45 (2), 259-294 (1993).

66 Tocchetti P, Tudone E, Marier JF et al. Pharmacokinetic profile of defibrotide in patients with renal impairment. Drug Des. Devel. Ther. 10, 2631-2641 (2016).

67 Richardson PG, Elias AD, Krishnan A et al. Treatment of severe veno-occlusive disease with defibrotide: compassionate use results in response without significant toxicity in a high-risk population. Blood 92(3), 737-744 (1998).

68 Richardson PG, Murakami C, Jin Z et al. Multi-institutional use of defibrotide in 88 patients after stem cell transplantation with severe veno-occlusive disease and multisystem organ failure: response without 
significant toxicity in a high-risk population and factors predictive of outcome. Blood 100(13), 4337-4343 (2002).

69 Chopra R, Eaton JD, Grassi A et al. Defibrotide for the treatment of hepatic veno-occlusive disease: results of the European compassionate-use study. $\mathrm{Br}$. J. Haematol. 111(4), 1122-1129 (2000).

70 Richardson PG, Soiffer RJ, Antin JH et al. Defibrotide for the treatment of severe hepatic veno-occlusive disease and multiorgan failure after stem cell transplantation: a multicenter, randomized, dose-finding trial. Biol. Blood Marrow Transplant. 16(7), 1005-1017 (2010).

- Defibrotide $25 \mathrm{mg} / \mathrm{kg} /$ day in four divided doses was identified as the appropriate dose for trials in adult or pediatric patients with veno-occlusive disease.

71 Sucak GT, Aki ZS, Yagcí M et al. Treatment of sinusoidal obstruction syndrome with defibrotide: a single-center experience. Transplant. Proc. 39(5), 558-563 (2007).

72 Corbacioglu S, Greil J, Peters C et al. Defibrotide in the treatment of children with veno-occlusive disease (VOD): a retrospective multicentre study demonstrates therapeutic efficacy upon early intervention. Bone Marrow Transplant. 33(2), 189-195 (2004).

73 Triplett BM, Kuttab HI, Kang G, Leung W. Escalation to high-dose defibrotide in patients with hepatic veno-occlusive disease. Biol. Blood Marrow Transplant. 21(12), 2148-2153 (2015).
74 Corbacioglu S, Carreras E, Mohty M et al. Defibrotide for the treatment of hepatic veno-occlusive disease: final results from the international compassionate use program. Biol. Blood Marrow Transplant. 22(10), 1874-1882 (2016).

75 Bearman SI, Anderson GI, Mori M et al. Venoocclusive disease of the liver: development of a model for predicting fatal outcome after marrow transplantation. J Clin. Oncol. 11(9), 1729-1736 (1993).

76 Richardson PG, Smith AR, Kernan NA et al. Early initiation of defibrotide treatment from time of diagnosis of hepatic veno-occlusive disease/sinusoidal obstruction syndrome is associated with improved survival post hematopoietic stem cell transplantation; a post-hoc interim analysis. Presented at: $21 s t$ Congress of the Asia-Pacific Blood and Marrow Transplantation Group (APBMT). Singapore, 29-30 October 2016.

77 Kernan NA, Richardson PG, Smith AR et al. Efficacy and safety of defibrotide (DF) in the treatment of hepatic veno-occlusive disease/ sinusoidal syndrome (VOD/SOS) following chemotherapy in an ongoing study. Presented at: The European Society for Blood and Marrow Transplantation. Valencia, Spain, 3-6 April 2016 (Poster P683).

78 Grupp SA, Smith AR, Triplett BM et al. Timing of initiation of defibrotide post-diagnosis of hepatic veno-occlusive disease/sinusoid obstruction syndrome post-hematopoietic stem cell transplantation: exploratory age group analysis from an expanded access study. Presented at: 58th ASH Annual Meeting \& Exposition. San Diego, CA, USA, 3-6 December 2016. Publication number: 66.

Tekgündüz E, Kaya AH, Bozdağ SC et al. Does defibrotide prophylaxis decrease the risk of acute graft versus host disease following allogeneic hematopoietic cell transplantation? Transfus. Apher. Sci. 54(1), 30-34 (2016).

80 Corbacioglu S, Pagliuca A, Grupp S et al. Protocol for a phase 3 , randomized, adaptive study comparing the efficacy and safety of defibrotide vs best supportive care to prevent hepatic veno-occlusive disease/sinusoidal obstruction syndrome (VOD/SOS) in adult and pediatric patients undergoing hematopoietic stem cell transplant (HSCT). Presented at: 2016 ASH Meeting on Hematologic Malignancies. Chicago, IL, USA, 16-17 September (2016).

81 Corbacioglu S, Carreras E, Niederwieser DW et al. Defibrotide study group. safety of defibrotide (DF) in stem cell transplant (SCT) patients (pts). Presented at: 52nd ASH Annual Meeting and Exposition. Orlando, FL, USA, 4-7 December (2010).

82 International Society for Medical Publication Professionals. GPP3 Guidelines (2015). www.ismpp.org/gpp3 